\title{
COMPARISON OF THE TIME COURSE CHANGES IN CEREBRAL BLOOD VOLUME AMONG DIFFERENT BIRTH WEIGHT GROUPS OF NEONATES DURING THE FIRST 3 DAYS OF LIFE
}

T. Fujioka, T. Takami, H. Ishii, Y. Suganami, D. Sunohara, A. Kondo, N. Mizukaki, E. Sakai, T. Miyajima, A. Hoshika

Department of Pediatrics, Tokyo Medical University, Tokyo, Japan

Aims: The aim of this present study is to compare the changes in cerebral blood volume (CBV) among term and preterm infants during the early postnatal period by using near infrared time resolved spectroscopy (NIR-TRS).

Method: Optodes were placed on the front of the head and the right upper arm of neonates. The cerebral total hemoglobin $(\mathrm{ctHb})$ level, peripheral total hemoglobin $(\mathrm{ptHb})$ level, and $\mathrm{SrO}_{2}$ were measured using NIRTRS at 3-6, 12, 24, 48, and $72 \mathrm{~h}$ after birth. The CBV, fractional cerebral tissue oxygen extraction (FTOE) and $\mathrm{ctHb} / \mathrm{ptHb}$ were calculated. The MABP, $\mathrm{HR}, \mathrm{SpO}_{2}, \mathrm{PCO}_{2}$, blood $\mathrm{Hb}$ level and $\mathrm{Ht}$ were measured. All the data were statistically analysed.

Result: Twenty-three term infants (term group) and 36 preterm infants (preterm group) were observed. The preterm group was divided into 2 subgroups: the LBW subgroup (21 infants; $1,500 \mathrm{~g}<\mathrm{BW}<2,500 \mathrm{~g}$ ) and the VLBW subgroup ( 15 infants; BW $<1,500 \mathrm{~g}$ ). The CBVs for the term group were significantly higher than those for the preterm group throughout the study period. The CBVs for the VLBW subgroup were significantly higher than those for the LBW subgroup at 24,48 and $72 \mathrm{~h}$ after birth. The ctHb/ptHb for the term group was significantly higher than that for the preterm group throughout the study period. $\mathrm{CBV}$ and $\mathrm{Ht}$ were negatively correlated in 3 groups.

Conclusion: The changes in the CBV pattern differed between term and preterm infants. The CBVs for VBLW infants were higher than those for LBW infants. 